\title{
A PUREZA DO SANGUE HÍBRIDO: OS BASTIDORES DO TURFE PARA A PRODUÇÃO DE CAVALOS E HOMENS DE CORRIDA
}

\author{
Rômulo B. Labronici ${ }^{1}$
}

\section{Introdução ${ }^{2}$}

As corridas de cavalo denominadas de turfe se apresentaram como um objeto expoente para observar e analisar algumas das questões referentes ao processo de domesticação e hibridização entre homens e animais. A comunhão entre um espetáculo esportivo e um mercado de jogos de azar produz uma estrutura elaborada que possibilita que jogadores participem das corridas mediante a constante produção de apostas. Com isso, as denominadas "casas de apostas" se estabelecem como espaços estratégicos que possibilitam um acompanhamento cotidiano das corridas. Neste sentido, esta modalidade de apostas, também chamadas de apostas "na pata do cavalo", se tornou o ponto de partida para compreender algumas nuances dos bastidores do turfe carioca.

O objetivo deste artigo é analisar como os apostadores do turfe utilizam saberes a partir dos bastidores das corridas em um intricando e complexo processo classificatório para apostar. Para um apostador experiente, a utilização de informações, conhecimentos e saberes referente a técnicas específicas é essencial para a produção de um bom jogo. Da mesma forma que, conhecer em detalhes os bastidores das corridas, e seus papeis institucionais, se faz necessário para a elaboração das estratégias de aposta. Ainda neste sentido, este trabalho visa a discutir uma noção de "domesticação" própria do turfe, onde homens e cavalos são moldados e controlados para o andamento das corridas.

Nas pistas, o cavalo e jóquei são muitas vezes entendidos como um agenciamento (Deleuze, 1995: 18) onde um não é passível de compreensão sem o outro. Sendo esta a unidade real mínima que produziria os enunciados das apostas. Ao firmar uma aposta realizada em um cavalo $\mathrm{X}$ ou $\mathrm{Y}$, entende-se como uma escolha dentre possibilidades em um determinado páreo. Entretanto, durante o processo de classificação utilizado pelos jogadores, o binômio natureza e cultura é paradoxalmente reforçado e desdobrado em polos de oposição complementares, e que podem ser lidos

\footnotetext{
${ }^{1}$ Universidade Federal Fluminense, Brasil.

${ }^{2}$ Este artigo é parte integrante de reflexões originadas em minha tese de doutorado defendida em 2016 no Programa de Pós-Graduação em Antropologia da Universidade Federal Fluminense (PPGAUFF).
} 
sob diversas óticas como: homem/animal, técnica/genética, performance/pedigree, domestico/selvagem; dentre muitos outros. Assim, por mais que se entendam que não há corridas sem que se tenha homens e cavalos correndo conjuntamente, o processo de avaliação e classificação para as apostas é feita separadamente, reforçando este binarismo.

Para a produção deste artigo, foi realizado um trabalho de campo que visou a um acompanhamento rotineiro de apostadores em casas de jogo, espalhadas pela cidade do Rio de Janeiro. Este acompanhamento buscou observar como o turfe é entendido em sua totalidade para a elaboração dos processos de produção de apostas. Assim, em vias de lançar uma luz a esta questão, proponho analisar três espaços específicos e seus papeis institucionais. Primeiramente haras e studs e seus criadores, em seguida o papel dos Centros de Treinamento (CT's) com seus treinadores e, por fim, a Escola Nacional de Profissionais do Turfe - ENPT e seus jóqueis. É preciso deixar claro que, mesmo fora de alguns destes espaços, apostadores que frequentam casas de jogo necessitam conhecer o funcionamento de grande parte da estrutura de produção das corridas para realizar uma boa avaliação nas apostas.

Deste modo, a partir dos discursos correntes nas casas de jogo, é possível afirmar que são os criadores, situados nos haras e studs, os principais responsáveis para a produção de um cavalo de corrida. Através de determinadas técnicas e avaliações genéticas específicas, selecionam e escolhem os "melhores" cruzamentos entre animais. Assim, é no haras, onde criadores buscam moldar a biologia do animal. Através de uma fecundação artificial se tem o intuito de diminuir casualidades genéticas na criação de futuros competidores. Em seguida, o segundo espaço institucional de importância são os Centros de Treinamentos (CT), e o papel de seus treinadores. São nestes espaços em que treinadores utilizam distintas técnicas de treino selecionadas ao longo da carreira dos competidores. A partir de uma tipologia biológica, treinos distintos são selecionados para cada tipo específico de animal. Por fim, analisarei a Escola Nacional de Profissionais do Turfe - ENPT (ou Escola de Aprendizes) que ensina e aperfeiçoa as técnicas de montaria a aprendizes (os futuros jóqueis e joquetas), domesticando tanto homens quanto animais para adequar as suas "respectivas naturezas" ao turfe. O ponto principal a ser analisado aqui é de como técnicas específicas são utilizadas nestes espaços, visando à domesticação de homens e animais na busca de uma adequação e “otimização da biologia” em função das corridas. Em um certo sentido, este trabalho 
busca entender como a relação da natureza selvagem do cavalo é posta sob a ótica da inferioridade, e que, através de um arcabouço de técnicas, busca ser superada em prol de uma campanha vitoriosa nas pistas.

E nisso, o conceito de "domesticação" é apresentado como uma necessidade para a continuidade desta prática. Tal conceito já vem sendo trabalhado por Tim Ingold (1976, 1980 \& 2011) a partir do âmbito das relações interespecíficas a partir das quais em seus trabalhos, a noção de domesticação passa a figurar como um modo de reposicionar a relação entre homens e animais. Desejando dar conta da diversidade de relações com os animais, que é detectada em um cenário etnográfico mais amplo, Ingold apresenta de forma crítica alguns conceitos de domesticação. Tendo em vista ajustar o uso dessa noção a meus objetivos, este trabalho busca apresentar o conceito de domesticação como uma aproximação a uma "cultura do turfe", onde homens e cavalos são constantemente moldados a partir do uso de técnicas distintas voltadas para a busca de um melhor desempenho nas pistas.

\section{Os especialistas}

Antes de mais nada, é preciso mencionar algumas observações acerca dos competidores envolvidos. Nas corridas de cavalo o ator de maior evidência é, sem dúvida alguma, o cavalo - e o seu protagonismo é evidenciado nos debates e discussões nas casas de jogo. A seguir, apresento a reprodução de uma conversa entre jogadores que discutem, além do cavalo, diversas aspectos das corridas de modo a explicitar o nível de entendimento e comprometimento de um jogador com o turfe. Em uma casa de apostas, o jogador João apresenta a sua leitura de um dos páreos no qual o jogador Pedro afirmava desconhecer os concorrentes em profundidade. João, que já foi aprendiz de jóquei, inicia sua explanação de maneira didática:

Nesse páreo aqui vai dar o sete, e deixa eu te falar porquê. Esse treinador, o Sampaio, geralmente se dá bem com as distâncias das provas porque é um dos caras que sabe a hora de botar o cavalo pra correr. Na moral, não dá pra sair enfiando qualquer cavalo em qualquer prova que vai perder feio. Esses caras que acham que um cavalo corre a porra toda da mesma maneira não sabem do que estão falando. Vagabundo fica tirando onda de que entende, que faz e acontece, mas só dão bola fora. Mermão, um cavalo é "especialista" em um tipo de corrida. Tem cavalo fundista, e tem outros que não aguentam uma corrida mais longa. Uns gostam de correr atrás e atropelar no final, já outros desenvolvem melhor largando desembestado na frente deixando todo mundo pra trás a corrida toda. Cabe o treinador e o jóquei verem quando é o melhor momento de botar o cavalo na pista e a melhor forma de correr a prova. 
Pedro, desconcertado e visivelmente sem graça responde:

Pô, eu pedi a sua opinião do páreo, não pedi pra você me dar uma aula de cavalos pô! Assim você me desmoraliza!

Em sua fala, João destaca principalmente alguns dos tipos distintos de cavalo de corridas: como as suas respectivas preferências e limites de suas performances nos diferentes tipos de provas. Além disso, é possível considerar que a "aula" de João explicita um outro lado do turfe, isto é, aquilo que não está em evidência e que é deixado nos bastidores das carreiras turfísticas, mas de grande importância no momento da elaboração de uma aposta. Nas carreiras hípicas é o cavalo que está em evidência no primeiro plano.

Assim, é preciso salientar que a raça dos cavalos utilizada no turfe é de um tipo específico para corridas denominada Puro Sangue Inglês (PSI) - ou Thoroughbread ${ }^{3}$ como chamam os ingleses - considerada a melhor raça de cavalo para esse esporte. Um dos principais motivos são suas pré-disposições genéticas que lhe dão capacidades aeróbicas excepcionais para manter altas velocidades em longas distâncias. Nascida da necessidade militar, a velocidade passou a ser um dos principais atributos no desenvolvimento e criação dos cavalos. Dos hunters ${ }^{4}$, massivos e lentos, aos cuirrassiers $^{5}$ de Napoleão, o desenvolvimento e a preocupação da cavalaria e da qualidade dos animais tornava-se cada vez mais presentes nos exércitos de vanguarda.

E com relação à prática de corrida, os processos que vieram a estabelecer os pilares do esporte tiveram início na Inglaterra com a criação do Jockey Club Inglês em 1750. Este período embrionário do turfe teve início a partir de uma maciça importação

\footnotetext{
${ }^{3}$ Segundo a antropóloga Rebecca Cassidy (2002: 9) em seu trabalho com o turfe em Newmarket (Inglaterra) considera os cavalos de corrida como uma categoria polissêmica: "Not animal, not person, not object, not subject, not entirely artificial and not entirely natural. The obtaining relationship between horses and racing society, in which racehorses are sometimes part of "nature" to be improved, sometimes part of a "nature" that includes humans, is comfortable" (Cassidy, 2002: 9).

${ }^{4}$ Raça de cavalo Irlandesa denominada de Irish Hunter. Deve-se destacar que não são uma raça especificamente, mas que correspondem a um tipo de cavalo com traços diversos e que não se conhecem com homogeneidade. Em todo o caso, pode falar-se de um corpo geralmente harmônico, forte e, sobretudo, bem proporcionado tanto nos cavalos pequenos como nos maiores. Existem 4 classes diferentes destes cavalos e que eles variam dependendo do cruzamento. Estes tipos são o pequeno, o ligeiro, o médio e finalmente os cavalos pesados.

${ }^{5}$ Os Cuirrassiers Napoleônicos eram cavalos equipados com armadura utilizados para batalhas. Sua montaria utilizava a espada como arma principal, deixando a pistola como arma secundária. Este tipo de montaria foi utilizado até o início da I Guerra Mundial (1914), quando foi substituído por veículos modernos. Atualmente, uma função estritamente cerimonial.
} 
de garanhões árabes e bérberes que viriam a fixar os pilares da criação da raça PSI. Especula-se que tenham sido utilizados o sangue de mais de 400 desses animais. De modo a organizar e catalogar as diferentes raças em 1793 instaurou-se o Stud book ${ }^{6}$ que, além de outras coisas, estabeleceu um ordenamento da atividade, fixou calendários, regras das disputas, estabeleceu tabelas de peso por idade e sexo e, principalmente, adotou o conceito de que só se poderia participar dos confrontos animais cujas origens estivessem identificadas no próprio Stud Book ${ }^{7}$. Apesar do nome "Puro Sangue", um cavalo PSI na verdade se trata de um híbrido ${ }^{8}$. Entretanto, isto em nada altera o seu prestigio entre as demais raças devido a sua destacada capacidade física para a corrida.

\section{Os haras e os criadores de cavalos}

Além de custosas, a criação e a (re)produção de um PSI é algo que exige espaço, cuidados e técnicas especiais para que o animal possa se desenvolver sem perder as características necessárias para um esporte de alto desempenho. Atualmente, a criação destes animais é considerada uma arte: “(...) a criação do cavalo de corridas é uma arte que aproxima os homens do que há de mais solene e plácido na natureza (Barcellos, 2002: 21) 9 . Tais criações são, em geral, realizados nos espaços institucionais

\footnotetext{
${ }^{6}$ Stud Book é o organismo que se ocupa de elaborar e guardar os registros dos PSI. Cada cavalo tem sua genealogia e campanha nas pistas oficiais compilada nos seus livros, que, no Brasil é administrado pela Associação Brasileira de Criadores e Proprietários do Cavalo de Corrida - ABCPCC. A fim de estabelecer o controle dos cavalos, uma carteira de identidade é produzida para cada animal e, geralmente, se mantém sob o poder do treinador, e que acompanha animal em suas movimentações oficiais, como: entrada e saída de um hipódromo, apresentação para um páreo ou viagens entre hipódromos e centro de treinamento. Além do stud book, é estabelecido o "Certificado Nacional de Propriedade e Performance", que descreve os dados básicos do animal como filiação, nascimento, criação e seus respectivos registros; além de apresentar em diagrama as características físicas e sinais particulares de cada animal assim como um histórico de toda a campanha do cavalo, com detalhes dos páreos que participou, seus respectivos resultados, assim como as transferências de propriedade.

${ }^{7}$ Ver: (Barcellos, 2002: 15)

${ }^{8}$ O PSI por ser um produto da mistura de sangues de origens diversas dentro da mesma espécie guarda características marcantes de seus primeiros ancestrais. Tais características podem ser melhor notadas observando, principalmente, a forma e o tamanho da cabeça dos animais: a testa convexa e as orelhas pequenas, normalmente viradas para dentro, corresponde a dos cavalos árabes que estão na origem da raça: a côncava, julgada rude pelos puristas, provém da linhagem bérbere do norte da África. Nenhum desses sinais estéticos, porém, significa qualquer garantia de performance nas pistas. Ver: (Barcellos, 2002: 15 )

${ }^{9} \mathrm{O}$ antropólogo Tim Ingold (1980: 95) afirma que mesmo que várias espécies possam ser domadas e incorporadas ao grupo dos humanos, isto não demandaria, em uma relação mais ampla, o controle pela sua reprodução. Ou seja, em uma das concepções de domesticação apresentada pelo autor não requer que os animais sejam "morfologicamente domesticados". Entretanto, no caso do turfe, os animais não apenas são domesticados em sua reprodução, como o sistema de criadores de PSI foi construído para que a reprodução fosse manipulada e controlada passo a passo pelo homem. Criadores controlam "com rédeas curtas" todo o processo de reprodução de animais para as corridas.
} 
denominados de haras, studs ou mesmo sob cuidados de pequenos proprietários particulares.

Para um apostador aficionado em corridas de cavalos, um haras não é apenas o local de criação de um cavalo de corrida. É lá que ele adquirirá as características necessárias de um vencedor. São nestes espaços que os conhecedores de cavalo irão estabelecer, a partir de um rigoroso processo de avaliação e cruzamento, os animais ideais para cada corrida. Os processos constituídos nos haras proporcionam meios para o desenvolvimento da "personalidade do animal". Os haras, são assim entendidos como espaços onde, segundo a descrição de Sergio Barcellos (2002), passam um ar de aconchego e tranquilidade com uma diversificada quantidade de árvores e flores para ampliar a sensação de paz e o prazer visual:

(...) as veredas que dão acesso à casa principal são formadas por pilares de nogueiras, cedros e salgueiros, cujo cimos se entrelaçam em gigantescos arcos para sombrear o caminho. Onde a copa das árvores mais novas ainda não se desenvolveu o suficiente, brechas na folhagem deixam passar cones de luz, como nas rosáceas de antigas catedrais, criando no chão zonas alternadas de claridade e sombra. Espalhadas por esses corredores naturais, folhas secas em todos os matizes de vermelho sangue, cobre o ouro, acolchoam o solo e tornam silenciosa a passagem por ali de pessoas e animais, como se todos estivessem usando pantufas e temessem ofender a majestade do lugar. Ao final das veredas, a arquitetura dos jardins junta surpresa ao enlevo da caminhada. Rosas e cravos plantados em círculos concêntricos, as brancas ao centro, depois as amarelas, depois os cálices rubros nas extremidades, fechando os anéis de dezenas de serpentinas do mesmo formato, as corolas entumecidas pelas milhares de pétalas da primavera. Prolongando o delírio visual, alfazemas roxas - lâminas farpadas na ponta dos caules em lança - se misturam em completa desordem aos misótis, quaresmas, papoulas e azaléias para prolongar o oceano cromático e fazer crer ao visitante que ele se encontra às portas do paraíso (Barcellos, 2002: 22-23).

Considerados lugares especializados de descanso e de reprodução, "as portas do paraíso" são redutos de campeões e devem proporcionar ao animal todo o cuidado necessário para que ele, assim como qualquer atleta, possa desenvolver o seu máximo na próxima corrida.

A criação dos cavalos PSI é feita nos haras especializados para o turfe a partir de um cruzamento genético de animais com um pedigree selecionado. Tal seleção pode ser feita com cavalos competidores na ativa ou aposentados. Em muitos casos, competidores que adquiriram status em sua carreira, quando aposentados, são diretamente selecionados para a reprodução. Seu material genético pode ser (re)vendido a outros haras que desejam realizar cruzamentos com a genética de seus próprios 
cavalos. Haras que se notabilizam como "construtores" de renomados PSIs de forma continuada adquirem um status diferenciados que alcança as casas de apostas. Como afirmou jogador Ivan:

O [Haras] Santa Maria [de Araras] só tem foguete! Geralmente eles não colocam cavalo em qualquer páreo não, fica só no final de semana mesmo. Quando tem cavalos de lá correndo nem precisa se preocupar que a chance de dar merda é ínfima. Pode apostar que vai ser uma boa corrida.

A exemplo do Haras Santa Maria de Araras (RS), que atualmente é considerado um dos melhores haras do país e que possui constantemente cavalos na elite do turfe nacional, é também notável o desempenho de alguns sutds, como por exemplo os studs T.N.T e Avarenga. Entretanto, apesar de todo trabalho genético para a criação de um cavalo de corrida, o cronista e aficionado Sergio Barcellos (2002: 15-16) afirma que bons cavalos dependem também da observação e da intuição dos criadores.

Parece evidente que afluência econômica para garantir as melhores terras e acesso às boas matrizes e linhagens conta muito; entretanto, é a capacidade de combinar de modo efetivo todas essas variáveis que faz a diferença entre o fracasso e sucesso no desempenho do ofício (Barcellos, 2002: 16)

A relação do local destinado para a criação e o pedigree são fatores que se apresentam diretamente ligados. Haras que possuem cavalos com maior pureza de pedigree são sempre mais cotados no momento das apostas. Pois é também a partir da experiência do criador que se desenvolverá um cavalo mais competitivo, logo, não é possível avaliá-los separadamente no momento de se fazer uma aposta. O prestigio adquirido pelo haras é transmitido a seus cavalos e vice-versa. Isto se dá devido a forma com que os jogadores entendem a criação de um PSI. Segundo o jogador João:

Juntar dois cavalos bons aumenta muito as chances de sair coisa que presta, mas juntar cavalo ruim, com cavalo merda é praticamente impossível sair algo decente!

Como afirmou o jogador, o cruzamento de dois cavalos campeões não implica em um novo futuro campeão, haja visto que as técnicas de produção passam pela chave da "tentativa e erro". Junta-se a genética de dois cavalos considerados bons para que aumente as chances de produzir um potro de qualidade equivalente ou superior. Mesmo 
não havendo garantias para que isso ocorra, um haras com bons cavalos será visto como contendo maiores possibilidades de produção de bons cavalos.

Caso um cruzamento "dê errado", os animais podem ser vendidos para outros proprietários fora do turfe, encerrando definitivamente a carreira de corredor, ou podem ser leiloados no Tattersall $^{10}$ e destinados a outros proprietários ${ }^{11}$ de cavalos de corrida que podem inserir os animais em provas menos concorridas. Assim, o prestigio de um haras não se limita a um único cavalo, mas pela totalidade de seus animais. Criadores com um repertório de cavalos vitoriosos serão dotados de um prestigio que refletirá na imagem do haras através do desempenho de seus competidores. Assim, a combinação de: espaços especializados, técnicas específicas e profissionais qualificados constitui o primeiro passo na "linha de montagem" de um cavalo de corrida.

\section{$O$ treino a partir de tipos genéticos}

Como afirmei anteriormente, a habilidade natural de um cavalo de corridas é informada pelo seu pedigree, um dos principais fatores responsáveis pelo bom desempenho de uma performance. No entanto, o tipo de treinamento a que o animal for submetido será tão ou mais responsável por suas vitórias e derrotas. Pois, como afirmou o jogador João, não se adotam as mesmas preparações para animais que corram distâncias com velocidade distintas, pois cada animal é considerado "especialista” em algum tipo de corrida. Do mesmo modo, o cronista Sergio Barcellos (2002) afirma:

Esta constatação [distinção de performances entre velocidade e distância] obriga o treinador a inteirar-se das aptidões e potencialidades do animal, o que implica conhecer suas origens, a forma como foi criado, as características e o modelo funcional dos ascendentes (Barcellos, 2002: 32).

\footnotetext{
${ }^{10}$ Richard Tattersall foi um jóquei inglês que, em 1780, fundou o Hyde Park em Londres, o primeiro estabelecimento destinado exclusivamente a efetuar leilões de cavalos para o turfe. Seu nome transformou-se em nome genérico para designar locais apropriados de leilões de cavalos. No Rio de Janeiro, o Tattersall do hipódromo da Gávea é administrado pela Associação de Proprietários de Criadores de Cavalos de Corrida do Rio de Janeiro - (APCCC) e nele são realizados os principais leilões da cidade. (Ver: Carvalho 1998 ${ }^{\mathrm{a}}$ : 24)

${ }^{11}$ Segundo Frederico Tesio os proprietários de cavalos de corrida se dividem em três categorias: "os que amam o cavalo, os que amam o jogo, e os que amam a ascensão social através dos cavalos, os "snobs" no sentido etimológico do termo - "sine nobilitatem." (Tesio, 1979 apud Barcellos, 2002: 62).
} 
Assim, o entendimento entre a herança genética do animal e o tipo de treino aplicado são considerados fundamentais para o funcionamento de um cavalo competitivo. O seu desempenho é dado a partir da imposição do ritmo de treinamento imposto por treinadores ${ }^{12}$ em Centros de Treinamentos (CT). Apesar de fisicamente se estabelecerem fora das pistas, os treinadores são um dos personagens principais no turfe. Eles são os profissionais encarregados de preparar os animais para as carreiras e responsáveis, ao lado dos jóqueis, pelo bom desempenho nas corridas. Segundo Carvalho (1998a) os treinadores:

(...) são autênticos hoteleiros responsáveis últimos pelo tratamento que os cavalos recebem em suas cocheiras, além das estratégias de treinamento e desenvolvimento dos animais durante a carreira. Uma vez iniciado o páreo, só resta aos treinadores torcer para que o desempenho de cavalo e jóquei conduza à vitória, para que eles possam, também, comparecer ao "winner's circle", para comemorar mais um sucesso (Carvalho, 1998a: 92).

Como qualquer técnico esportivo, é ele quem escolhe o momento preciso no qual o atleta deve entrar em ação. É ele que deve saber se o animal está em condições físicas ideais para ser inscrito em um determinado páreo, dar instruções ao jóquei e tecer estratégias a serem desenvolvidas ao longo da carreira ${ }^{13}$.

O papel "fundamental” dos treinadores é realizar um treinamento que seja em função das características biológicas do animal, respeitando a distinção entre cavalos de curta (sprinters), longa (stayers) e uma milha (mile, ou milheiros) de distância ${ }^{14}$. Estas

\footnotetext{
${ }^{12}$ Em seu trabalho com o turfe, Marvin Scott (1968: 49-77) apresenta diferentes tipos ideais de treinadores baseados nas escolhas e estilos de treinamento.

${ }^{13}$ Carvalho (1998 ${ }^{\mathrm{a}}$ : 107) aponta para muitas das incertezas na carreira de um treinador de corrida. Os seus proventos financeiros, além de incertos, dependem da performance de seus pensionistas na pista, pois só através dela que o treinador consegue alavancar e desenvolver sua carreira. Seus êxitos, e sua teia de amizade angariam mais serviços e, portanto, mais remuneração. A ele ainda sobressai a incumbência de assumir compromissos, contratar cavalariços e outros empregados, e adquire rações e insumos diversos, despesas que são repassadas para o proprietário sob o rótulo de custo do trato. Entretanto, a remuneração de um treinador é variável, pois depende da participação nos prêmios, em vitórias e colocações, a não ser quando um treinador possui um contrato de exclusividade, que o vincula mediante condições especiais e alguma grande coudelaria ou Centro de Treinamento (CT).

${ }^{14}$ Sergio Barcellos (2002: 32-56) aponta para a importância do condicionamento aeróbico do animal, e que significa expandir a capacidade pulmonar e ampliar os níveis de bombeamento do sangue, mantendose inalterado o diâmetro das fibras musculares. Os cavalos tipo "sprinters" tem de adaptar suas reservas anaeróbicas a um ritmo significativamente mais intenso, e estar preparados para suportar um débito maior de oxigênio durante a disputa. Mais ainda, suas fibras musculares necessitam de um diâmetro ampliado, sem que, não se realizam as explosões de velocidade necessária à performance em distâncias curtas. Assim, a herança genética, a partir do conhecimento sistematizado do pedigree que provém a forma mais segura de explorar as potencialidades dos cavalos de corridas. Os melhores sprinters são compactos, com jarretes próximos ao chão, de quartelas curtas e pronunciada massa muscular, indispensável à geração da energia requerida pela abordagem das pequenas distâncias. "Levando aos extremos biomecânicos, o
} 
tipologias são derivadas tanto do pedigree quanto do tipo de treino ao qual o animal é submetido. Um dos principais "erros" atribuídos aos treinadores é o da inversão do treinamento com os parâmetros de habilidades naturais do animal. Neste sentido, cabe aos treinadores a responsabilidade pela boa avaliação e adequação entre a origem genética, modelos de treino e os tipos de distância em cada prova. Por serem os que convivem diariamente com os animais, os treinadores têm a possibilidade de sentir as reações dos cavalos de modo mais nítido e se responsabilizam pela escolha dos páreos nos quais cada animal sob seus cuidados irá atuar. A fim de estabelecer uma escolha das distâncias ideais, os treinadores utilizam: a tabelas de distâncias médias de cada uma das correntes de sangue, o modelo biofísico (sprinters, stayers e milheiros), estatísticas sobre a progênie dos reprodutores, as análises das campanhas nas pistas, indicações de pistas de preferência (areia ou grama) e a forma como atuam os principais ascendentes. Estas são algumas das ferramentas utilizadas por treinadores voltadas para o melhor andamento das provas.

E, com isso, em busca de uma otimização cada vez maior do desempenho dos animais foram desenvolvidos os Centros de Treinamento $\left(\mathrm{CT}^{\prime} \mathrm{s}\right)^{15}$, espaços de treinamento intensivo que podem estar conjuntamente ligados a um haras específico ou serem espaços exclusivos para tal fim. No Rio de Janeiro os principais CT’s estão situados na região serrana em conjunto com os principais haras do Estado. Em geral, possuem grandes espaços com a capacidade para mais de cem cavalos de uma só vez. Proprietários particulares podem "alugar" espaços nestes centros para que seus animais sejam treinados. Ao contrário dos haras, a ação vitoriosa de seus treinadores não implica em uma fonte direta de prestígio a um CT. Cavalos estabelecidos em CT's podem ser vistos como dotados de uma incompletude imanente que demandam um constante treinamento. Por mais que o treinamento não seja visto como um objetivo fim ou algo conclusivo, "estar em treinamento" ou estar em um CT remete a uma falta de

modelo físico de velocidade pura nos equinos é o do "quarto de milha". Em aparência e funcionalidade, os melhores "quartos-de-milha" estão muito próximos dos thoroughbreeds especializados em tiros curtos" (p.53). No caso dos cavalos tipo "stayers" são feitos para suportar peso e cobrir maior espaço de terreno. Ele é mais alto, que comprido, de dorso curto e elevado, grande perímetro toráxico, jarretes retos e quartelas longas. As diferenças notórias na estrutura dos dois modelos obrigam, por sua vez, a formas diferentes de galopar e treinar. Por fim, a classificação dos milheiros, que possuem a aptidão para corridas de uma milha $(1609 \mathrm{~m})$ de distância. Correr a milha, exige do animal, antes de tudo, uniformidade e ritmo, além de tempos rigorosamente certos na colocação, principalmente quando se trata de percursos em linha reta, onde qualquer quebra na cadência do galope geralmente anula as possibilidades de vitória.

${ }^{15} \mathrm{O}$ conceito de "Centro de Treinamento" (CT) para o turfe foi importado da Itália a partir do sucesso do renomado turfista Frederico Tessio. No turfe fluminense, o conceito foi introduzido por Júlio Capua nos anos 1960 no Vale do Cuiabá distrito do município de Petrópolis. 
amadurecimento da personalidade do animal e que deverá ser posta à prova em cada corrida. Haja visto que, sob a ótica de um apostador, não teria porquê um animal "realmente bom", não ser inserido nos grandes e prestigiosos haras e studs.

Assim, a partir da ação destes atores em espaços institucionalizados com técnicas voltadas para um melhor andamento das corridas, busca-se lapidar a natureza do animal para que ele se transforme em um ser exclusivo a uma única finalidade: ganhar o máximo de corridas. E quanto maior o seu prestigio, maior o seu valor comercial e maior será, também, o volume de apostas realizadas nas casas de jogo.

\section{Escola de jóqueis}

Nesse sentido, creio ser importante apresentar o jóquei como um último ator cuja atuação está sob a mira dos apostadores, haja visto que é ele quem "controla" e corre juntamente com o cavalo. Como perguntou retoricamente um dos jogadores da casa de apostas do Largo do Machado: "E quem ganha, o homem ou o cavalo?"

O papel relevante dos jóqueis chega a se equivaler ao dos animais no sentido de sua atuação desde a largada até a linha de chegada. Os holofotes estão direcionados à performance desses jóqueis, sendo suas reputações profissionais colocadas à prova a cada volta na pista. Caso não sejam contratados por algum haras ou proprietário, os jóqueis são sorteados para atuar nos páreos e, a cada corrida, poderão montar cavalos diferentes. Da mesma forma, poderão correr várias vezes por dia, o que dificulta o entrosamento necessário que um jóquei deveria ter com a sua montaria. Essa é uma dificuldade que não ocorre com jóqueis contratados por algum haras ou stud que correm frequentemente com os mesmos cavalos, adquirindo assim um maior entrosamento com o animal e, consequentemente, conseguindo melhores desempenhos.

Segundo o jóquei Juvenal Machado da Silva, os aspectos mais relevantes da profissão, além da necessidade de se apresentar em condições físicas ideais, se estabelecem no conjunto das técnicas de montaria, quais sejam: a absoluta sincronia de movimentos, o uso do chicote ${ }^{16}$ para alertar, o controle total da cabeça do animal, a

\footnotetext{
${ }^{16}$ No Turfe, o uso do chicote é muitas vezes confundido com o aumento da velocidade ou da cadência da passada do animal, entretanto, segundo as regras de montaria, o chicote somente deve ser usado para alertar. Caso um jóquei chicoteie muitas vezes o animal ao longo de uma corrida ele é tido como merecedor de ser submetido ao mesmo tratamento.
} 
pressão adequada do bridão ${ }^{17}$, a escolha de um caminho certo entre as opções possíveis e o equilíbrio (apud: Barcellos, 2002: 99). Sendo a preocupação com o ritmo e o equilíbrio o principal cuidado ao longo de uma prova. O primeiro para evitar descompassar a passada do animal e o segundo para manter o centro de gravidade (do jóquei e do animal conjuntamente) o menor possível. O conhecimento destas técnicas de montaria se dá a partir de uma transmissão escolar para os futuros profissionais.

Geralmente jóqueis iniciam suas carreiras profissionais na Escola Nacional de Profissionais do Turfe - ENPT, ou "Escola de Aprendizes" que, desde os anos 1950 forma os jóqueis que vão correr na Gávea ou em outros hipódromos nacionais e internacionais. Este se estabelece como um espaço que ensina e treina técnicas de montaria para jovens que desejem tentar a profissão de competidores nas carreiras hípicas. Com as rédeas nas mãos, os jóqueis são os profissionais do turfe mais visados e sua performance coloca em jogo a sua própria reputação, a remuneração dos outros profissionais envolvidos, os interesses econômicos dos proprietários e a vitória dos apostadores. Segundo Carvalho (1998a) os jóqueis partilhariam uma característica em comum, que seria:

(...) o gosto pela vida no dorso de um cavalo de corridas. Não se encontra aquele que faça isso apenas por dinheiro, como se fosse um trabalho qualquer. Eles trazem quase sempre, no sangue o amor pelo turfe. Pais, tios e primos foram, ou ainda são, também, profissionais nos hipódromos. Não obstante é preciso o dom para conduzir. Nem todas as pessoas conseguiriam controlar um animal, que pesa em média 490 $\mathrm{kg}$., quando o próprio condutor deve manter seu peso em torno de $55 \mathrm{~kg}$. (Carvalho, 1998 : 98)

Iniciado na ENPT, os aprendizes se distinguem dos demais profissionais com suas jaquetas e capacetes "amarelo vivo", nas calças e botas azul índigo e possuem nos trabalhos e galopes matinais (iniciados geralmente às 5 da manhã) suas verdadeiras aulas práticas. Têm entre 15 e 20 anos de idade e cerca de 50 quilos de peso ${ }^{18}$. A idade e o peso, tanto na carreira do cavalo como na carreira de um jóquei, se tornam prejudiciais à medida que aumentam com o tempo. Tentativas para o seu controle são constantes ao longo de sua carreira ${ }^{19}$. Do contrário, a profissão pode terminar precocemente como afirmou o ex-jóquei João que, entre outros motivos pelos quais ele não seguiu a carreira, destacou: "Não deu mais. Cresci muito, pra cima e pros lados".

\footnotetext{
${ }^{17}$ Um tipo de freio utilizado em montarias.

${ }^{18}$ Ver: (Carvalho, 1998: 30)

${ }^{19}$ Ver: (Cassidy, 2002: 108)
} 
O controle do peso (e também da altura) é assim apresentado como tão importante quanto o domínio das técnicas de montaria. O seu controle é considerado como um dos principais fatores para a vitória. Correr com um jóquei mais pesado remete a um maior esforço que o animal terá que realizar ao longo de uma prova. E como no caso de João, o tamanho, assim como o peso, pode ser determinante para o término de uma carreira profissional no turfe ${ }^{20}$.

Assim, ao longo da "linha de montagem" de uma corrida, a relevância da performance dos jóqueis chega a se equivaler a dos cavalos, e depende de procedimentos de controle constantes. A maestria das técnicas de montaria e o controle do próprio corpo são fatores definidores entre um bom jóquei e um ruim. Tendo em vista essa correlação, o volume apostado em uma casa de jogo pode variar em função disso. Embora homens e cavalos sejam avaliados separadamente, e antes do início de cada corrida, é no conjunto de suas performances que se estabelece a distinção entre a vitória e a derrota.

\section{Linha de chagada}

Deste modo, a partir dos discursos correntes nas casas de jogo, é possível afirmar que o entendimento que os apostadores possuem das corridas ultrapassa a corrida em si. Um jogador experiente aponta para a necessidade de se entender o que ocorre além das linhas de largada e chegada. A atuação dos criadores, treinadores e jóqueis nos haras, centros de treinamento e escola de aprendizes, nesta ordem de importância, são de extrema relevância para a escolha de uma aposta. Pois são nestes espaços que distintos atores acionam técnicas que são utilizadas sempre com o intuito da busca de um melhoramento no desempenho.

Deste modo, a noção de domesticação no turfe envolve a necessidade de um controle constante. Controles que vão desde os espaços e técnicas (criação, treino e montaria), perpassando a totalidade da vida profissional dos competidores (animal e o jóquei). Há um esforço constante para evitar deixar a intervenções do acaso. A pretensa centralidade da natureza que domina o campo do imaginário do esporte através da

\footnotetext{
${ }^{20}$ Aprendizes e jóqueis que tenham encerrado suas carreiras podem dar continuidade no Jockey Club adquirindo trabalho de cavalariço, ou, caso adquiram um conhecimento necessário, podem se tornar futuros treinadores.
} 
figura do equino, é posta para um segundo plano quando observada sob a ótica das constantes tentativas de manipulação do homem. A domesticação exigida para se produzir cavalos e homens de corrida perpassa por etapas cuidadosamente planejadas para se construir as "máquinas", ou os "foguetes" de corrida, potentes, eficientes, destituídos de espírito ou natureza, contendo apenas velocidade.

\section{Referências}

BARCELOS, Sergio. Cavalos de corrida: uma alegria eterna. Rio de janeiro: Topbooks. 2002 CARVALHO, Ney O. R. (editor). O Turfe no estado do Rio de Janeiro. Imprinta Gráfica e Editora. Rio de janeiro, $1998^{\mathrm{a}}$.

CASSIDY, Rebecca. The Sport of the kings. Kinship, class and thoroughbred breeding in Newmarket. Ed. Cambridge University Press, 2002.

\& MULIN, Molly. Where the wild things are now. Domestication reconsidered. Oxford, The Werner Green Foundation Ed. 2007.

DELEUZE, Gilles, FÉLIX, Guattari. Mil platôs - capitalismo e esquizofrenia. vol 5. Ed.34, São Paulo, 1997, 4ª reimpressão, 2008

INGOLD, Tim. The Skolt Lapps Today. Cambridge: Cambridge University Press. 1976. . Hunters, pastorialists and ranchers: reindeer economies and their transformations. Cambridge: Cambridge University Press. 1980. 2011. . Being Alive: essays on movement, knowledge and description. London: Routledge.

SAUTCHUK, Carlos Emanuel. e STOECKLI, Pedro. O que é um humano? Variações da noção de domesticação em Tim Ingold. In.: Anuário Antropológico, 2011/II - Dezembro, 2012.

Recebido em: 08/08/2016. Aprovado em: 05/12/2016. 